\title{
El busker visto por la \\ ciudadanía: actitudes hacia la música callejera en España
}

\author{
Alicia Martínez Gil \\ Doctora en Industrias Culturales y de la Comunicación. Universidad Politécnica de València. \\ alimartinezgil.arte@gmail.com
}

Recibido: 12/02/2020 Evaluado: 29/03/2020 Publicado: 20/06/2020

\section{RESUMEN}

En este artículo examinaremos los resultados de un breve estudio de actitud a los ciudadanos, a la par que desarrollaremos el grado de intercambio y satisfacción que existe de la música callejera en España.

Las continuas regulaciones y el nuevo uso de los espacios urbanos han puesto en conocimiento a la música callejera, poniendo en valor su categoría artística y cultural. El público, además de establecer los criterios entorno a esta práctica, expone las problemáticas de convivencia social que genera esta actividad.

PALABRAS CLAVE: Espacio público; arte callejero; sociología urbana; música callejera

\section{ABSTRACT}

The busker seen by citizens: attitudes towards music street music in Spain

In this article, we will examine the results of a brief study of citizens' attitudes, while developing the degree of exchange and satisfaction that exists of street music in Spain.

The continuous regulations and the new use of urban spaces have added value street music as artistic and cultural category. The public, in addition to establishing the criteria surrounding this musical practice, exposes the problems of social coexistence that this activity generates.

KEYWORDS: Public Space; Strert Art; Urban sociology; street music 


\section{RESUM}

El Busker vist per la ciutadania: actituds cap a la música de carrer a Espanya

En aquest article examinarem els resultats d'un breu estudi d'actitud als ciutadans, al mateix temps que desenvoluparem el grau d'intercanvi i satisfacció que existeix de la música de carrer a Espanya.

Les contínues regulacions i el nou ús dels espais urbans han posat en coneixement a la música de carrer, posant en valor la seva categoria artística i cultural. El públic, a més d'establir els criteris entorn a aquesta pràctica, exposa les problemàtiques de convivència social que genera aquesta activitat.

PARAULES CLAU: Espai públic; art de carrer; sociologia urbana; música de carrer.

\section{INTRODUCCIÓN}

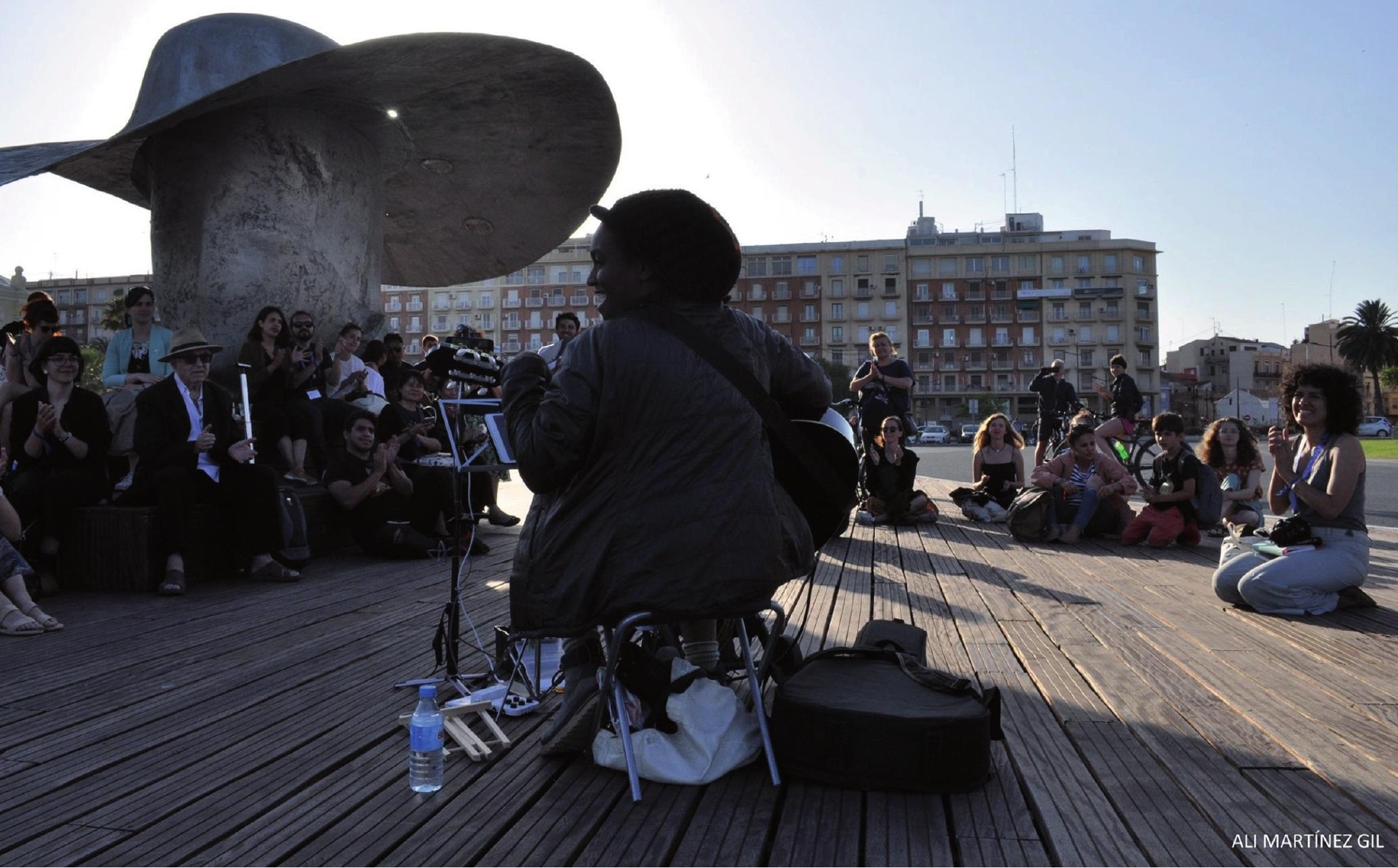

Ilustración 1: Dan Dann. Place Making Week Europe. Puerto de València. 2019. Alicia Martínez Gil.

La música callejera en España cuenta con mayor visibilidad desde hace algunos años. El apogeo turístico y las nuevas políticas culturales están poniendo en movimiento una actividad informal, fuera de los canales habituales de audición. Desprovista de una aparente justificación que no sea pedir en la calle, hay diversas hipótesis sobre su concepción. 
Aunque ya existía constancia de una figura musical en la Antigua Roma que deambulaba amenizando ceremonias, esta no fue reconocida como "músico callejero" hasta la Baja Edad Media con la aparición del trovador, que permaneció desde el 1100 al 1300 en las regiones del sur de Francia, extendiéndose más tarde a Italia y España. Como ejemplo de relevancia social, Eduardo IV creó el primer gremio de trovadores reales al servicio de la Corona Inglesa en 1469, ya que el movimiento en ferias, mercados y actos donde se relacionaban con la multitud era continuo (Brayshay, 2005). También, hallamos durante esta época, algunos hechos que ponen de manifiesto esta actividad.

La música sacra alcanzó su máximo esplendor con el desarrollo de la lírica y la escritura, que permitió su divulgación entre las diferentes abadías y monasterios. Es, en estos espacios, donde apareció un tipo de clerici vagante que se distanció del dogma eclesiástico, los goliardos. Este colectivo minoritario ${ }^{1}$ compartió con sus compañeros coetáneos el placer y la inspiración de la vida bohemia en obras musicales tan esenciales en nuestro repertorio clásico actual como Carmina Burana² (Martínez, 1996)

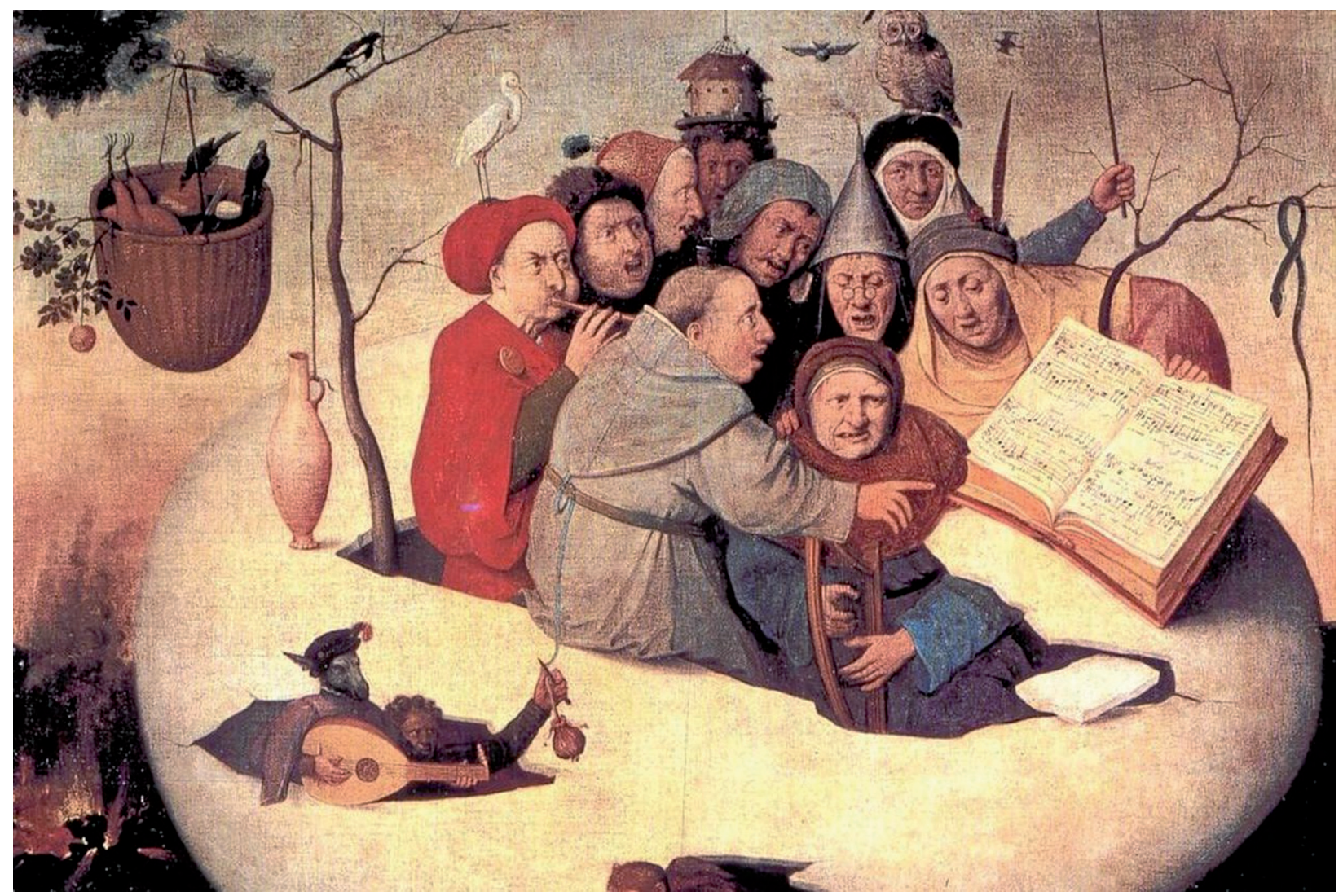

Ilustración 2: Concierto en el huevo. Anónimo y El Bosco. 1560. Palais des Beaux-Arts de Lille.

En el caso de España, hallamos diversas muestras de música callejera en algunos hallazgos, como el zafonero de Betanzos, un cuadro del siglo XVII que representa uno de los primeros testimonios de músico vagabundo que germinó en las ferias de esta localidad de A Coruña (Núñez-Varela y Lendoiro, 1946).

1.- Los goliardos, mayoritariamente, estaban formados por estudiantes pobres de las universidades del siglo XIII, que defendían el avant-la lettre como modelo de vida más cercano al conocimiento espiritual (Marcos, 1997).

2.-Carmina Burana compone el manuscrito hallado en 1803 en la abadía benedictina de Benedikthbeuern y supone una de las obras más exitosas e interpretadas de nuestro tiempo. 


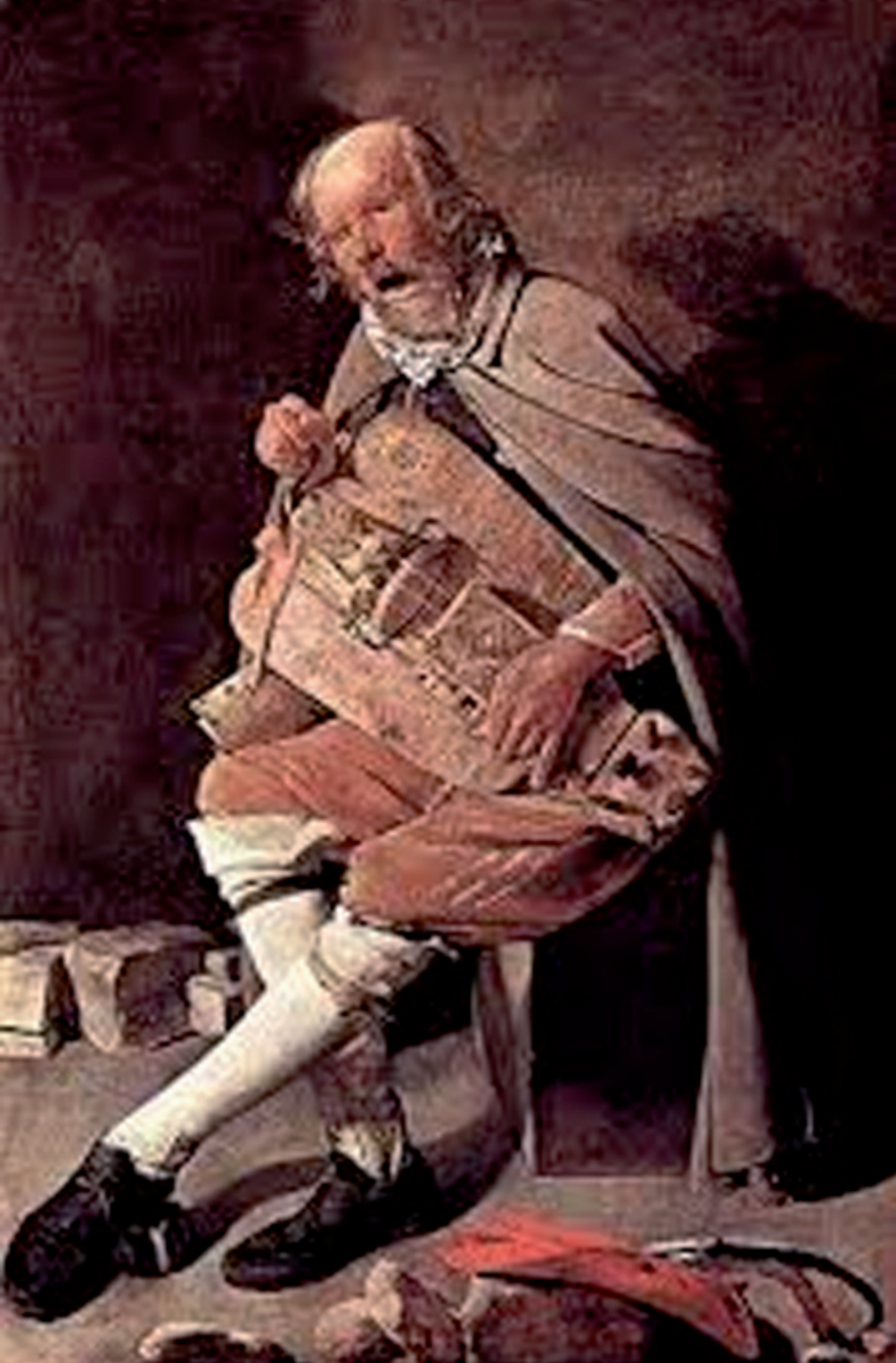

Ilustración 3: Le Vielleur. Georges de La Tour, 16301650. Musée d'arts de Nantes.

Durante largo tiempo, la música callejera gozó de una respuesta positiva por parte del público y se convirtió en uno de los entretenimientos al aire libre más visibilizados de nuestra historia. Pero, a la vez que el músico callejero se integraba en la sociedad a través de las clases más bajas como público potencial, un problema mayor iba creciendo a medida que esta actividad continuaba coexistiendo en las ciudades.

Así como Inglaterra permitió, con una serie de leyes y decretos, la actividad callejera como un servicio a la comunidad, fueron sus propios gobernantes, e incluso la ciudadanía, quien terminó por establecer órdenes para controlar y regular su expansión.

En "Pasajes de un filósofo" (Bennett, 2019), Charles Babbage ${ }^{3}$ redactó una carta, apoyada por otros intelectuales de su tiempo como Charles Dickens, donde manifestaba su desagrado ante las molestias callejeras que padecía a diario e impedía el desarrollo de sus actividades científicas.

En un grabado de 1741, del artista inglés William Hogarth, podemos observar como a través de una escena cómica, el exceso de ruidos de la ciudad es el resultado del que hablaba Babbage y por la cual el violinista profesional de la ventana no puede ejecutar sus lecciones.

Este fenómeno fue vinculado con los cambios del paisaje urbano que cada vez se iba extendiendo más con la proliferación de las actividades económicas y sociales.

En el siglo XIX, la industrialización y los sucesivos actos legislativos para controlar el aumento de las masas y ruido trajeron la desaparición gradual del músico callejero hasta nuestros tiempos, que se vió forzado a acatar una serie de órdenes de regulación que poco a poco fueron eclipsando su actividad.

Actualmente, el movimiento busking, ya conocido en casi toda Europa, ha ido encontrando su lugar en algunas ciudades donde se gestiona el arte callejero, con un orden y calidad negociados entre los artistas y la administración. Desde Bolonia hasta la propia Londres, la música callejera ya cuenta con toda una serie de ordenanzas, plataformas de acción y actividades de promoción que revalorizan su función social como actividad de entretenimiento y cohesión social.

3.- Prestigioso científico y matemático inglés del siglo XVIII. 


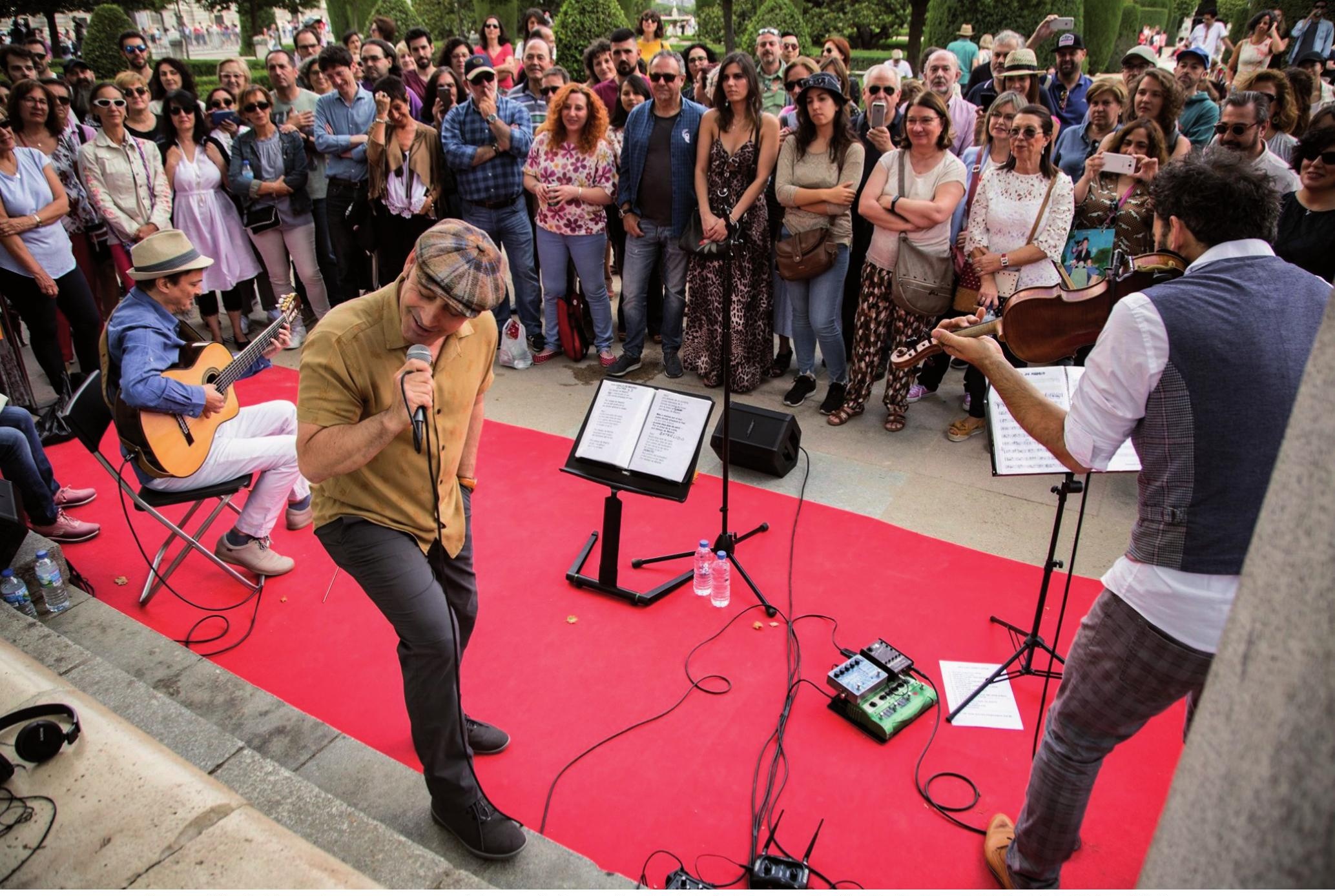

Ilustración 6: Zenet jutno a otros músicos callejeros. Festival de Primavera de "La Calle Suena". Madrid. 2019. Flávio Henrique Silva e Sousa.

España, a diferencia de Europa, lleva varias décadas gestionando el espacio público con la implantación de ordenanzas que, en algunos casos, restringe demasiado la actividad del músico como es el caso de València (Garsán, 2019). También, se han realizado algunos festivales que se mantienen a flote gracias al voluntariado y el trabajo de diferentes colectivos y asociaciones como Elx al carrer ${ }^{4}$ o las Noches Bárbaras ${ }^{5}$. La proliferación de plataformas como "La calle suena" de Madrid", la Asociación de Músics al Metro i al Carrer (AMUC) en Barcelona o la comunidad de "Musicarte Urbano" en València ${ }^{8}$ ha permitido avanzar en dicha labor aunque con finales diferentes. Madrid consiguió aprobar la primera ordenanza consensuada entre músicos, hosteleros y vecinos del Distrito Centro de Madrid. En cambio, AMUC estableció un convenio colaborativo

4.- Festival de artes de calle que se realiza en Elche. Surgió en el 2006 y se lleva realizando desde hace 14 años. Disponible en: $h$ ttps://elxalcarrer.com/

5.- Ciclo de conciertos que se inició en 2005 con el objetivo de celebrar el solsticio de verano y el Día Internacional de la Música, dando escenario a los músicos callejeros en el Círculo de Bellas Artes de Madrid. Disponible en: https://www.circulobellasartes.com/espectaculos/las-noches-barbaras/

6.- Colectivo formado por músicos y artistas cuyo interés es promover e impulsar el diálogo, la convivencia y la cultura reflexionando sobre las problemáticas vinculadas a la música callejera encontradas en el Distrito Centro de Madrid. Disponible en: http://lacallesuena.es/

7.- Entidad cultural sin ánimo de lucro que organiza al colectivo de artistas que tocan en el metro de Barcelona. Se fundó a mediados de los 90 , cuando un conjunto de artistas se unieron para tratar de armonizar y organizar las actuaciones musicales en el espacio público de Barcelona. Disponible en: $h$ ttps://amucbcn.org/

8.- Asociación, sin fines de lucro, que ampara a músicos y artistas callejeros de València, velando por sus derechos, y brindando apoyo y difusión. Actualmente se encuentran en negociaciones con el Ayto. de València para cambiar la ordenanza. Disponible en: https://www.facebook.com/musicarteurbano/ 
con la empresa de Transporte Metropolitano de Barcelona y actualmente trata de trasladar esta gestión al Ciutat Vella. En València, a pesar de los esfuerzos asociativos del colectivo, no se han conseguido grandes progresos y se hallan a la espera de un cambio en la ordenanza reguladora.

Aunque existe un gran número de casos positivos de los que tomar ejemplo, la continua aparición en medios de comunicación por las numerosas problemáticas de gestión ha evidenciado el conflicto entre el músico y la ciudad por mucho tiempo. El ejemplo más notorio lo encontramos en Madrid.

El desarrollo de las pruebas de idoneidad de la concejala Ana Botella, desembocaron críticas muy incendiaria entre el colectivo de artistas de la ciudad, ya que violaba muchos de sus derechos para hacer uso del espacio público (Torres, 2011). Este acontecimiento generó un tiempo de incertidumbre en el cual los diferentes colectivos de músicos de calle consiguieron decretos temporales que no vieron salida a una ordenanza justa y permanente hasta 2019.

Actualmente, el cambio de gobierno ha vuelto a paralizar la actividad callejera, reduciendo los permisos y poniendo en cuestionamiento los intereses políticos sobre los cívicos, ya que hay que recordar que el proyecto fue aprobado bajo petición conjunta del colectivo de músicos, las asociaciones de vecinos y las asociaciones de hosteleros (Mos, 2020).

\section{MARCO TEÓRICO}

En cuanto al músico y la ciudad se refiere, el punto de vista de la sociedad en la que coexiste es imprescindible. Según Pol y Valera (1994), los lugares físicos pueden configurar la identidad social de una comunidad. Con ello, no solo se lleva a cabo un construcción social, sino que se establece un diálogo de continuas sinergias en lo que denominaríamos "escenarios urbanos". Estos paisajes reciben el flujo constante de movimientos sociales tales como la inmigración, la gentrificación, el asociacionismo o el turismo que modelan su identidad.

Tanto en la configuración ambiental como espacial, el sonido es tratado equívocamente de ruido y no como un generador de experiencias. Algunas ciudades de UK como Bristol, Canterbury o Bath ya están potenciando esta forma de vivir la ciudad a través de la música callejera. Sus políticas buskers han dotado de estructura a una actividad con largos años de tradición. Los nuevos usos del suelo han permitido remodelar las ciudades respetando no solo su patrimonio arquitectónico y artesano, sino adaptarlo a las nuevas necesidades ciudadanas, en las cuales se incluye a los músicos callejeros como un patrimonio público.

Un ejemplo de las necesidades de estudiar sonido y espacio lo encontramos en Ciutat Vella de Barcelona. La necesidad de evitar la marginalidad y resistencia de los vecinos con los músicos de calle ha derivado en múltiples estudios y proyectos. En el artículo de Clúa, Llorca-Bofí y Psarra (2020), encontramos los resultados de una investigación acústica de campo sobre este distrito y sus puntos más favorables para la música en la calle. Junto a otras iniciativas municipales y 
sentimiento de control y seguridad o destruirlo. Hay que recordar que, como hemos visto en el contexto histórico, nos hallamos ante un agente que entre otras características es también un vecino que coexiste en el espacio urbano (Remesar et al, 2006).

La participación es una tendencia natural del ser humano por sentirse parte de algo, aunque también existe un nivel de complejidad en esta participación por la variedad de respuestas y la necesidad de una elección unilateral. El contexto que estamos estudiando difiere en ciertos posicionamientos que no siempre son compartidos y, por esta razón, hemos planteado el presente artículo.

OBJETIVOS.

En base al contexto histórico y el marco teórico expuestos, pasamos a establecer los propósitos que deseamos alcanzar en este artículo:

- Analizar la música callejera vista por los consumidores: los usuarios de la calle forman este público determinante en la toma de decisiones de la gestión política de la ciudad. Ayudan a enmarcar los factores que deben cumplirse para una convivencia responsable.

- Comprobar que grado de valoración existe de la música callejera como una actividad cultural: muchas son las manifestaciones artísticas que están adueñándose del espacio urbano y la música callejera forma parte de este proceso creativo.

\section{METOdOLOGÍA.}

Partiendo de unas premisas sobre la música callejera y su repercusión en la ciudadanía, estructuramos una metodología de encuesta. Para ello, registraremos la opinión de los usuarios de la calle y describiremos los resultados obtenidos. Hemos de destacar que la participación como encuestador de la investigación busca compartir experiencias y mantenerse en contacto con los diferentes procesos para adquirir una doble perspectiva siempre objetiva.

Al efecto, escogeremos una serie de técnicas de investigación que se adecuen a nuestras necesidades:

- Realizar una encuesta a los usuarios de las calles de Madrid, Barcelona y València, para explorar su punto de vista sobre el tema.

- Desarrollar los resultados obtenidos con el apoyo de referencias bibliográficas que hagan alusión a los fenómenos sociológicos de la música en la calle.

La encuesta es "una técnica que utiliza un conjunto de procedimientos estandarizados de investigación mediante los cuales se recogen y analizan una serie de datos de una muestra de casos representativa de una población, del que se pretende explicar una serie de características" (Alonso, 2016). La estandarización de preguntas facilita su administración, se evitan descripciones excesivamente largas y proporciona la posibilidad de hacer estudios parciales. Por lo cual, 
la formulación de las preguntas se establecerá en 13 preguntas a realizar en tres ciudades. La ciudadanía resulta diferente en cada lugar y no queremos condicionar el resultado en un único caso.

Estas preguntas se confeccionarán en base al patrón de un primer estudio de la investigadora, iniciado en la ciudad de Barcelona (Martínez, 2014). Este preludio ha servido para añadir preguntas que no habían sido valoradas anteriormente, además de establecer preguntas con respuestas más precisas y ampliar el tipo de público entrevistado para obtener resultados más equitativos.

Las limitaciones que contemplamos cuando comenzamos esta investigación fue la incapacidad económica de viajar del encuestador a dos de las tres ciudades, ya que de una de ellas era residente. También la falta de participación obtenida a pie de calle al realizar la encuesta en su propia ciudad y en el primer estudio, nos llevó a considerar la opción online como medio de difusión de la encuesta (redes sociales, e-mails,...).

Para determinar el número de encuestas necesarias para obtener un estudio de alta fiabilidad (Abascal y Grande, 2005), estimamos que era necesario obtener un 99\% de fiabilidad y un 1\% de error. Por tanto, necesitábamos encuestar a 1152 personas. En aproximaciones, Barcelona cuenta con 1.620.809 habitantes, Madrid con 3.182 .981 y València con 787.808 (España, 2017). Para obtener un margen de error de un 1\%, nuestro trabajo implicaba un total de 9.513 encuestas.

Esta cifra resultaba inviable tanto por el tiempo como el alcance de contactos por lo que se optó por trabajar bajo el $5 \%$ de margen de error y un fiabilidad del $95 \%$.

Cuando se diseñó, la encuesta se pensó en la brevedad de las preguntas y las respuestas, así como un orden lógico que evitara saltarse temas y desorientara al encuestado. La estructuración de la misma se divide en cuatro bloques según el tipo de preguntas y que objetivo perseguían.

En primer lugar se divide la clasificación por grupos de edades, nacionalidades, residencia y sexo. Esto permite crear relaciones y divisiones según las características de cada encuestado.

En el segundo bloque, las preguntas plantean los gustos y cercanía con la música universal.

El tercero se centra en el desarrollo del tema a investigar, la reacción del usuario de la calle con la música callejera de forma específica.

Y por último, el cuarto bloque se pensó para verificar si a ojos del usuario los músicos cumplen con los puntos básicos de la ordenanza de la ciudad. 


\section{RESULTADOS.}

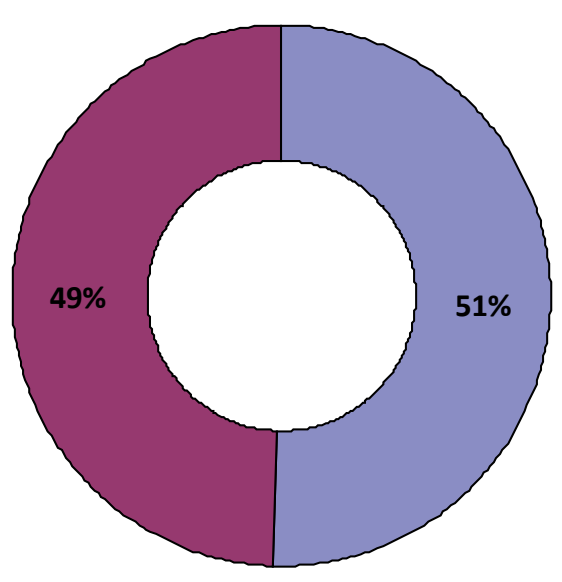

\section{Gráfico 1: Sexo de los encuestados}

El $51 \%$ de los encuestados son mujeres frente al $49 \%$ que son hombres, por lo que hemos conseguido obtener un número equitativo de encuestas por género.

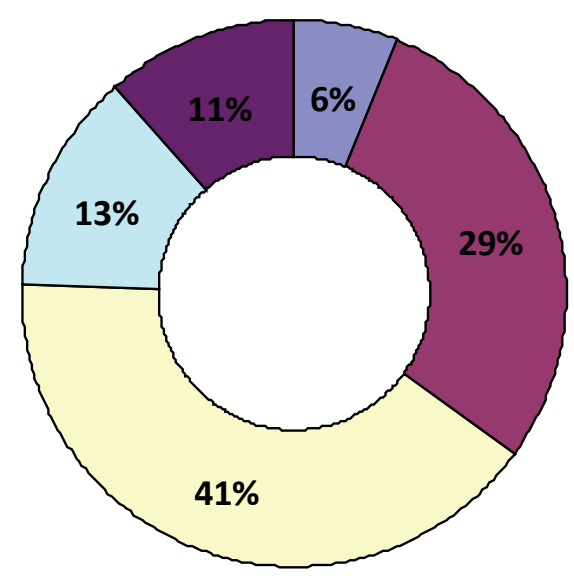

\section{Gráfico 2: Edad de los encuestados}

\begin{tabular}{|l|}
$\square-18$ \\
$\square 19$ A 29 \\
$\square 30$ A 49 \\
$\square 50$ A 59 \\
$\square 60$ \\
\hline
\end{tabular}

Los adolescentes con el 6\% (menores de 18 años) tienen inquietudes musicales y establecen, en gran parte, el consumo musical. A partir de los 19 a los 29 años, el 29\%, comienza a madurarse una concepción de música más afín a sus gustos. Su posición nos sitúa en las redes sociales, ya que es el grupo más activo (Mesa editorial Merca2.0, 2015). De 30 a 49 años encontramos el $41 \%$ de encuestados que, conforme avanzan en edad, aumentan sus responsabilidades de adulto, y pasan a ser un 13\% con los 50-59 años. Finalmente, la 3 o edad desvincula la mayor parte de su interés, destacando la perdida de capacidades auditivas en gente mayor de 70 años, así como su aislamiento en los espacios innovadores para la música, con el $11 \%$ de encuestados.

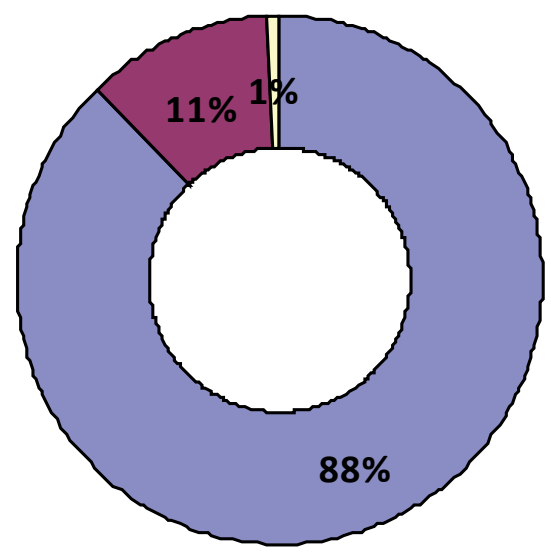

\section{Gráfico 3: Nacionalidad de los encuestados}

El 88\% de encuestados son españoles, ya la mayoría de usuarios de las redes sociales comprendía personas residentes o nacidas en España. Por otro lado, el $11 \%$ de respuestas vienen de gente extranjera procedentes de China, Australia, Siria, EEUU, Turquía, Armenia, Marruecos... (Estas últimas como las menos frecuentes), hasta países europeos como Francia, Bretaña, Alemania, Rusia, Países del Este, Portugal, Austria, Italia... Donde mayor número de resultados se ha obtenido ha sido en los países sudamericanos con Uruguay, Argentina, México, Cuba, Bolivia, Brasil, Colombia, Chile, Venezuela, Ecuador... Solo encontramos en un $1 \%$ a usuarios de la calle con doble nacionalidad. 


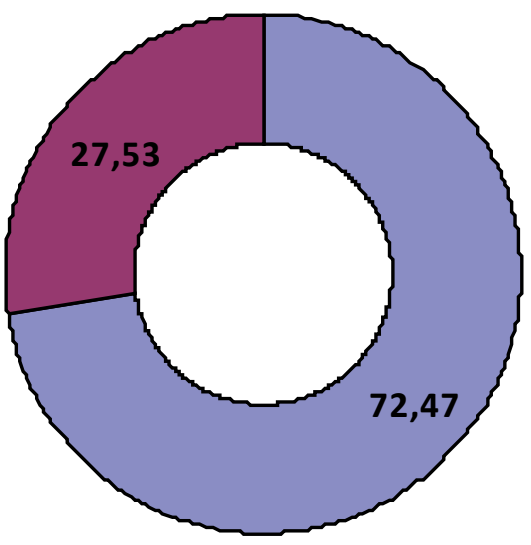

\section{Gráfico 4: Residencia de los encuestados}

El $72 \%$ de la gente es residente en España. Parte de esta población es de nacionalidad española por lo que era fácil que hubiera un mayor resultado de gente residente. A pesar de los resultados, el $28 \%$ no residen en la ciudad ya que puede venir dado tanto de la presencia de gente de otras localidades como a los turistas.

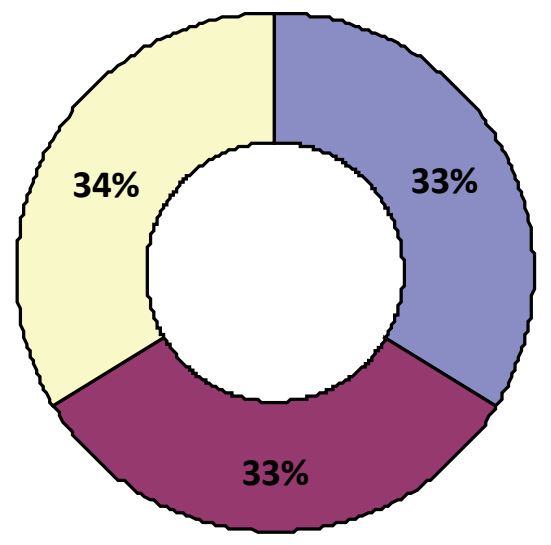

\section{Gráfico 5: Lugar de la encuesta}

En estos resultados podemos ver la igualdad aproximada de respuestas por ciudad encuestada. Esto no solo sirve para analizar los resultados por ciudades, sino para contemplar si hay diferencias destacables entre las respuestas de una ciudad y otra. Hay que recordar que ni el urbanismo ni el los habitantes tienen las mismas características de un lugar a otro. Aun así, en cuanto a topografía e historia, Barcelona y València comparten muchas características comunes. En cambio Madrid sale del patrón anterior al ser una ciudad de mayor poder económico y geográficamente interior. En València contestaron el 34\% de los encuestados, una diferencia del $1 \%$ con Madrid y Barcelona que tiene un $33 \%$.

\section{Gráfico 6: ¿Le gusta la música?}

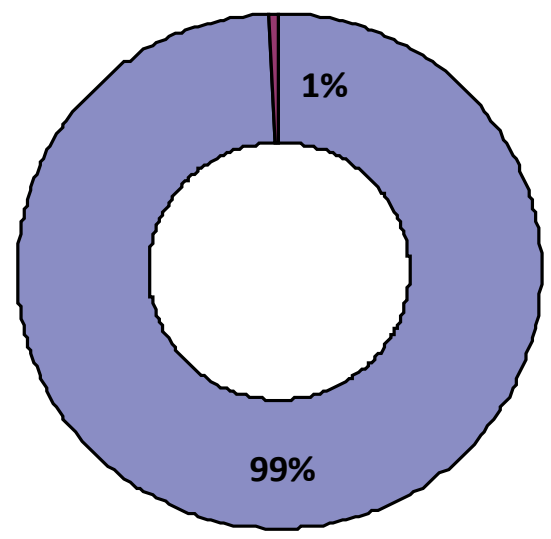

La música ha participado siempre en la construcción de buena parte de la vida social de las civilizaciones. Las prácticas musicales contienen un importante componente colectivo que siempre ha sido un elemento decisivo en la formación de asentamientos humanos (Blacking, 2006). Su consumo a lo largo de la historia resulta innegable. El $99 \%$ de los encuestados les guste la música, frente a un $1 \%$ que recoge el filtro de aquellas personas que pueden dar una connotación negativa a las respuestas restantes. 


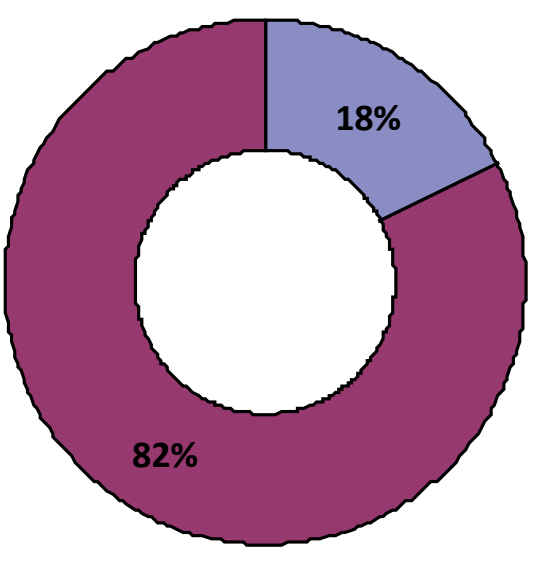

\section{Gráfico 7: ¿Es músico?}

Un músico puede empatizar, de forma comprometedora, con el tema al tratarse de una competencia propia. Por lo que esta pregunta filtraba esa cantidad de gente que está familiarizada con la música como profesión. El 18\% de los encuestados son músicos. En cambio, el $82 \%$ no lo son. Esta cifra resulta mucho más enriquecedora para la investigación ya que este público representa la imparcialidad, es decir, si el $82 \%$ de encuestados no son músicos y, por tanto, no corremos el riesgo de que los entrevistados muestren favoritismos hacia tocar en la calle ya que nunca habrán experimentado esa actividad en primera persona. No hay que olvidar que el público puede establecer las modas y, por tanto, la aceptación de una actividad fuera de los canales habituales de consumo.

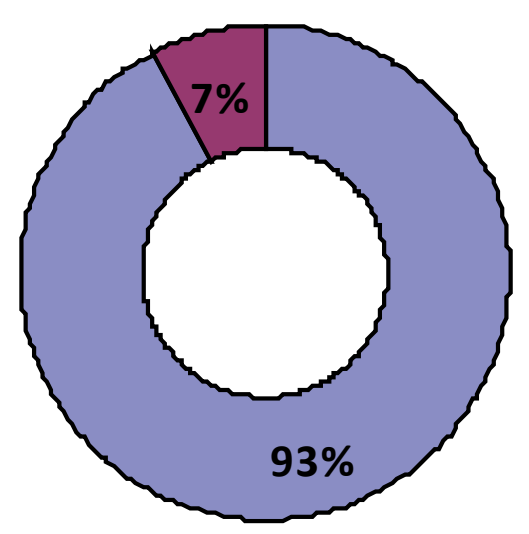

Gráfico 8: ¿Le gusta escuchar música de camino a su rutina diaria?

En la escucha diaria, muchos son los reproductores que se han fabricado para disfrutar la música y transportarla a cualquier parte. La figura del oyente, aun saliendo a la calle para abstraerse entre la multitud, continúa consumiendo una audición que, no hay que olvidar, se ha convertido en casi privada gracias a estos aparatos (Márquez, 2011). El 93\% de los encuestados escucha música de camino a la rutina diaria normalmente a través de su $\mathrm{mp} 3$ o radio, en cambio, el 7\%, afirma no escucharla por estos medios ya que no siente placer en ello. Muchos afirmaron que la música requiere de todos nuestros sentidos para poder ser disfrutada.

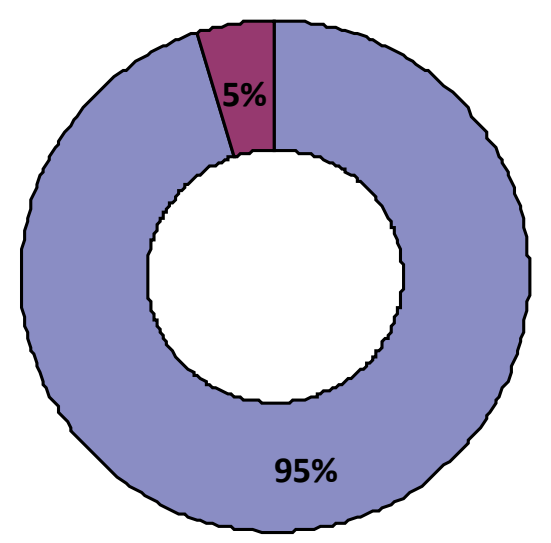

Gráfico 9: ¿Le gusta escuchar música interpretada en directo?

La música callejera forma parte de las actuaciones musicales contempladas para el directo. En los contextos urbanos, la música ha alcanzado una presencia innegable, una oportunidad para vivir esta experiencia que nos acompaña desde los inicios de la civilización en rituales y ceremonias sociales. El 95\% de encuestados escucha música en directo para recoger una experiencia. Aunque el $5 \%$ de los encuestados no suele escucharla, existe diferentes condicionantes para ello. La falta de tiempo o una economía poco sostenible son algunos de los motivos expuestos por los encuestados, aunque más adelante desarrollaremos otro condicionante en cuanto al consumo de música en directo. 

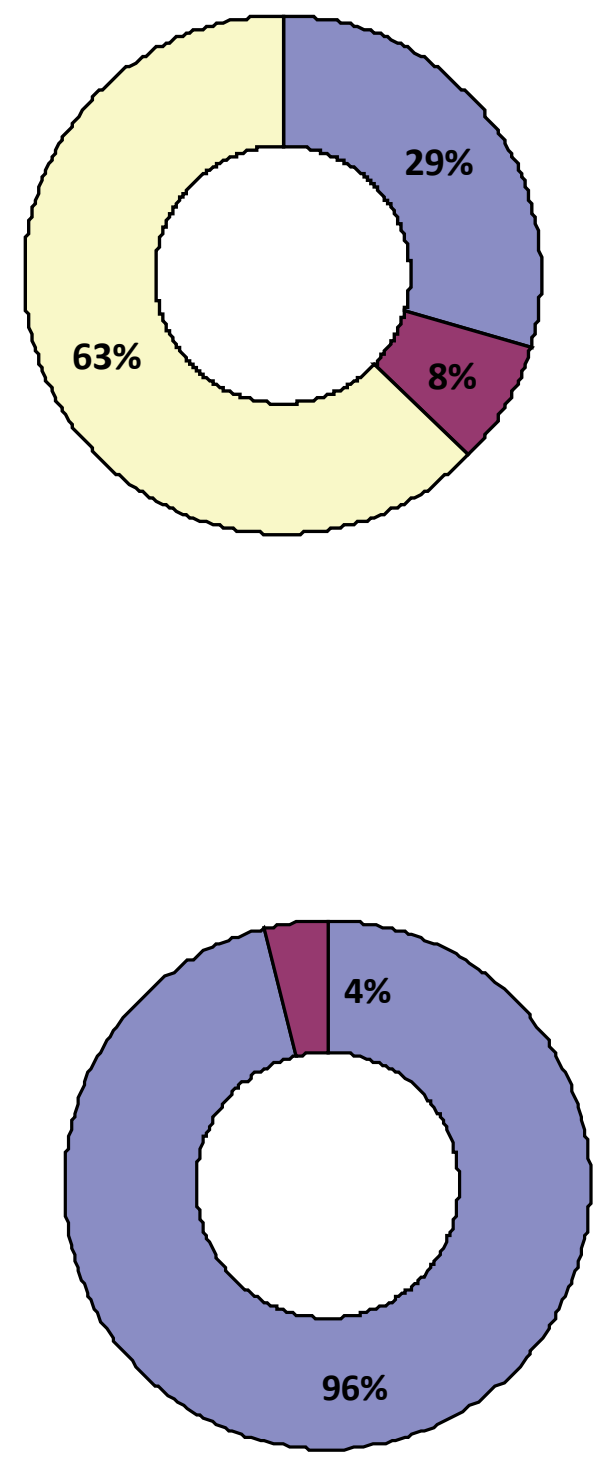

$2 \%$

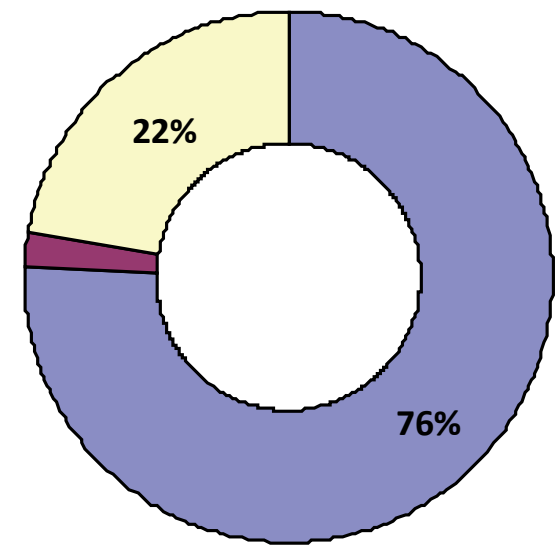

Gráfico 10: ¿Te paras a escuchar a músicos que interpreten música en la calle?

El motivo por el cual la gente se detiene a escuchar la música en la calle sigue resultando intrigante. Un encuentro fortuito, una atracción al sonido, una invitación previa... El 29\% de los encuestados siempre se para a disfrutar del sonido callejero que encuentra por su paso a la ciudad. En cambio, el $63 \%$ se detiene según la ocasión ya que no todo el mundo puede disfrutar de la música sin llegar tarde a sus puestos de trabajo u otras responsabilidades del día a día, sin contar, además, con una serie de factores que siempre van a ser decisivos para captar al oyente como el tipo de música, la calidad de la misma, la escenografía... Solo el $8 \%$ no se detiene. Quizás los ámbitos públicos de la música sean de otra predilección para este porcentaje que prefiere presenciarlos en otras circunstancias que no sea a pie de calle.

Gráfico 11: ¿Crees qué la música en la calle es también otra forma de arte?

El arte es más auténtico si resulta de un agente poco influenciado por academicismos o patrones. Con esta reflexión de Jean Dubuffet (1973), retomamos la importancia de la opinión de la ciudadanía como evaluadores de la música callejera pues no parten de prejuicios, más propios de profesionales del sector, sino de un juicio en base al saber más popular. El $96 \%$ de encuestados considera la música en la calle como otra forma de expresión artística, frente a un $4 \%$ que, probablemente, no la contempla dentro de los cánones establecidos del arte, tal y como lo conocemos, por los factores negativos que han sido apelados a la actividad descrita como el deambular urbano de una serie de artistas desfavorecidos de la sociedad.

Gráfico 12: ¿Te gusta que las calles sean ambientadas por músicos?

El transeúnte observa y participa en las acciones que acontecen en la calle, transformándose en un plano continuo de experiencias y emociones (Sennett, 2001).

La música callejera forma parte de estas acciones y la presencia del espectador puede promover o hundir el éxito de las mismas. La mayoría de encuestados, el $76 \%$, disfruta de la música en la calle, por otra 
parte, el 22\% alega que solo le gusta, a veces, según la calidad de la actuación. El 2\% no le gusta esta actividad, remarcando su condición de residente y que no siempre resulta agradable encontrar obstáculos en las calles o tener una actuación musical continua bajo su casa.

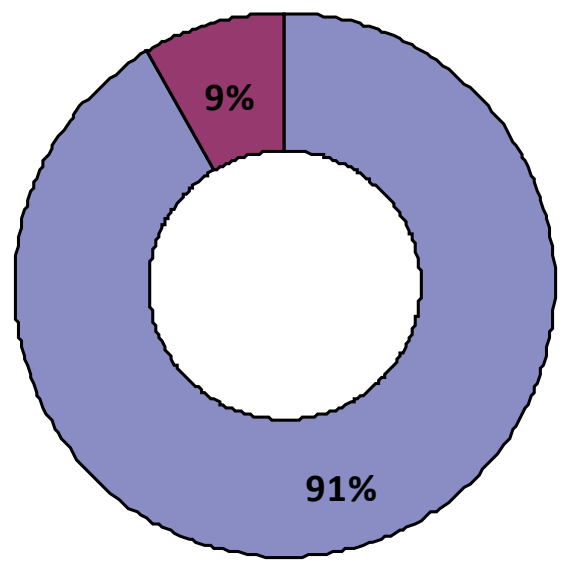

Gráfico 13: ¿Crees qué los músicos enriquecen el turismo de la ciudad?

Cuando observamos un paisaje cultural, construimos un concepto a través de nuestra mirada con diferentes juicios y experiencias. Pero hay que diferenciar al espectador entre el viajero en transición y el nativo que habita el territorio (Ferro, 2009). La complejidad y la diversidad de las ciudades que analizamos pueden cambiar según nuestra intencionalidad. No es lo mismo el nativo o vecino que convive a diario con los artistas de calle que el transeúnte puntual que está en la ciudad con una finalidad temporal. La presencia del turista es una figura capaz de convertir los desplazamientos en un estilo de vida (Bourriaud, 2009).

Así como el turista juega un papel de cambio y adaptación, la música también viaja y desarrolla este proceso. Las actuaciones callejeras, los festivales, los conciertos... todo ello traslada los sonidos en la consciencia del viajero y lo acompaña en la experiencia del lugar. Proporciono una narrativa emotiva que impide concebir esta experiencia en silencio ya que activa a los viajeros e impregna la duración de su viaje con numerosos recuerdos. Los vínculos entre turismo y música marcan la manera en que la música es buscada con frecuencia por los turistas a la hora de elegir las ciudades que serán visitas (Connell y Gibson, 2005).

A este fenómeno se le conoce como turismo musical y se ha convertido en una práctica polivalente que ofrece conocimientos sin límites espaciales (Cohen, Lashua y Schofield, 2010). Como parte de estas prácticas, conocer la aportación de la música callejera como actuación a pie de calle es importante. Así vemos que el $91 \%$ de los encuestados razonan que la música en la calle debe ser considerada como una expresión artística más de esta oferta turística, pues fortalece la promoción de la ciudad y la categoriza al nivel de otras ciudades más avanzadas en desarrollo cultural.

En cambio, el 9\% de los encuestados no comparten esta postura, aunque queda reducido en una minoría, probablemente por las valoraciones negativas que asocian "tocar en la calle" con "pedir en la calle". 

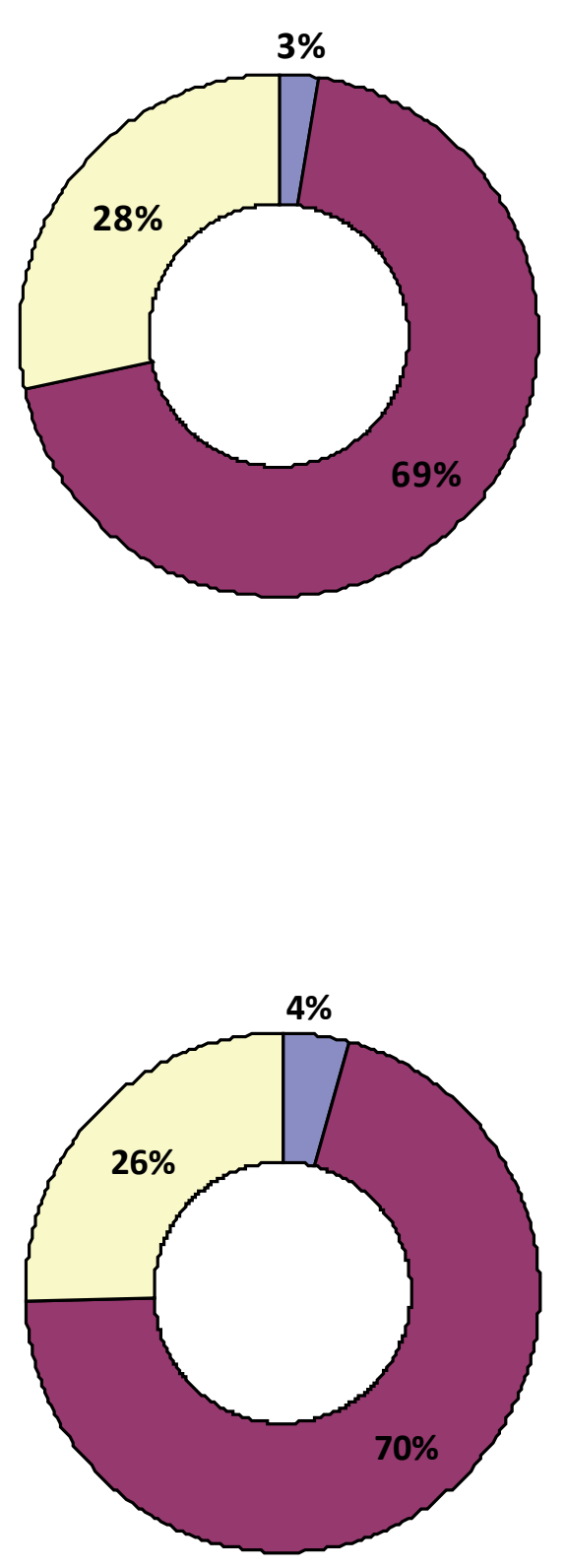

Gráfico 14: ¿Perjudican los músicos el tránsito de los viandantes?

Un ejemplo que podemos exponer de exceso de gente en las calles es Buenos Aires en 2009. La prensa "El Perfil" destacó el aumento de músicos que invadían las zonas más céntricas de la ciudad y que dificultaba transitar por las calles, especialmente a partir de las 18 de la tarde (Picún, 2013). A pesar de la mención de estos casos, nos resulta desconocida la opinión que se tienen los usuarios de la calle en cuanto al problema real que suscita la ocupación de un lugar por parte de un músico.

El 69\% de los encuestados no sienten molestias transitando por las calles donde se encuentran los músicos tocando. Por el contrario, el $3 \%$ alegó que sí les causaba un problema, y el $28 \%$ que, a veces, podía resultar un contratiempo para circular por la vía pública por el exceso de gente, según qué momentos. En su mayoría, los transeúntes sienten su espacio amplio y respetado por los músicos ya que cuando se detienen a tocar se ubican en rincones del casco histórico o calles amplias de paso.

\section{Gráfico 15: ¿Ocupan habitualmente espacios donde pueden molestar?}

Las ciudades actuales son el resultado de un proyecto de control que instaura un orden espacial. La diferencia entre el espacio gestionado por el Estado y la vida cotidiana ciudadana radica en las relaciones sociales que se construyen a través de las prácticas culturales y sociales.

El usuario del espacio determina la comunicación y negociación que se da en el mismo (Albán, 2008) y, por tanto, elabora, de acuerdo con la presencia de nuevos elementos culturales, un nuevo orden social que mantiene a la ciudad en constante actualización (Bourdieu, 2010).

Los músicos forman parte de la nueva cultural que aborda las calles y que, como tal, pueden alterar este orden social como puede ser con la invasión física del espacio. Como en los datos anteriores, vemos similitudes en la valoración de los usuarios. Con un $70 \%$, los encuestados no consideran que los músicos ocupen espacios donde puedan molestar, en cambio, el $26 \%$ comenta que, en ocasiones, no se respetan las normas de espacialidad de la calle y el 4,25\% afirma rotundamente que sí. 

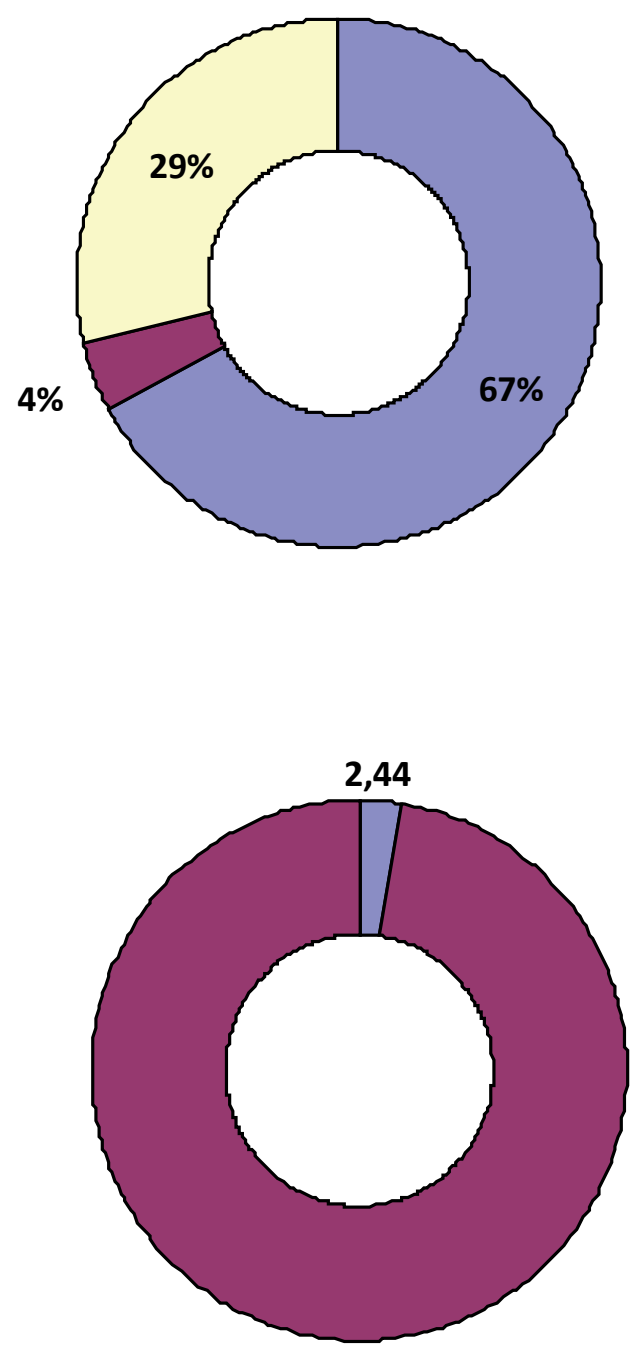

95,56

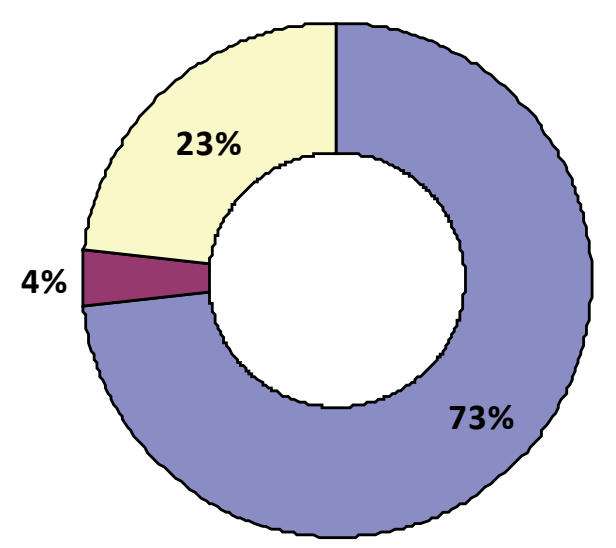

Gráfico 16: ¿Su presencia es adecuada cara a la gente?

Los prejuicios sociales sobre la actividad en la calle continúan atribuyendo connotaciones negativas a la música callejera. Hay que tener en cuenta que no deja de ser una actividad libre no demandada como producto, aunque la puesta en escena puede transformarla en una manifestación artística o performance a valorar. Aun así no se puede evitar que, para cierta parte del público resulte fuera de lugar ya dicho espectador reacciona ignorando la práctica (Silva E Sousa, 2017). El 29\% de encuestados considera, a veces, los músicos de calle no mantienen una presencia adecuada cara al público. El $4 \%$ de los encuestados piensa rotundamente que no. En cambio el $67 \%$ de los músicos si presentan un aspecto presentable.

Gráfico 17: ¿Has tenido algún problema con un músico por su trato?

El trato que haya recibido el público del músico es necesario para saber si existen condicionantes de la percepción que se tiene de la actividad. No deben descartarse agresiones y/o situaciones violentas. El $98 \%$ de encuestados no han tenido conflicto alguno, mientras que el $2 \%$ si ha experimentado alguna situación de incomodidad, en especial entre músicos.

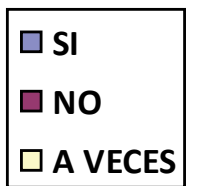

Gráfico 18: ¿El volumen al que suelen tocar los músicos en la vía pública es adecuado?

En 2002, la Unión Europea estableció la necesidad de un marco legal a nivel estatal para todos sus países miembros. En España se instauró la ley del ruido de 2003 que originó las actuales ordenanzas de contaminación acústicas de las ciudades españolas en un intento de preservar la tranquilidad vecinal y mejorar el rendimiento de los espacios ya contaminados. La excesiva presencia de sonidos puede interferir en la calidad del sonido que percibe el receptor y esto hace que la música se encuentre hoy en día descontrolada.

Este condicionamiento al que se ve sometida la música la puede llegar a confundir como contaminación acústica. El 4\% de los encuestados considera que los niveles de sonido de los músicos no son adecuados a esta situación, así como el 23\% que lo percibe en momentos puntuales. El 73\% afirma no sentir que la música callejera se exceda en sus volúmenes sonoros. 


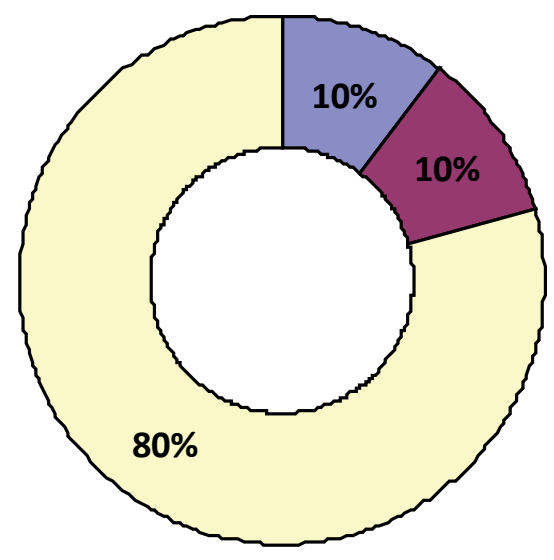

$\square$ SIEMPRE

$\square$ NUNCA

$\square$ A VECES
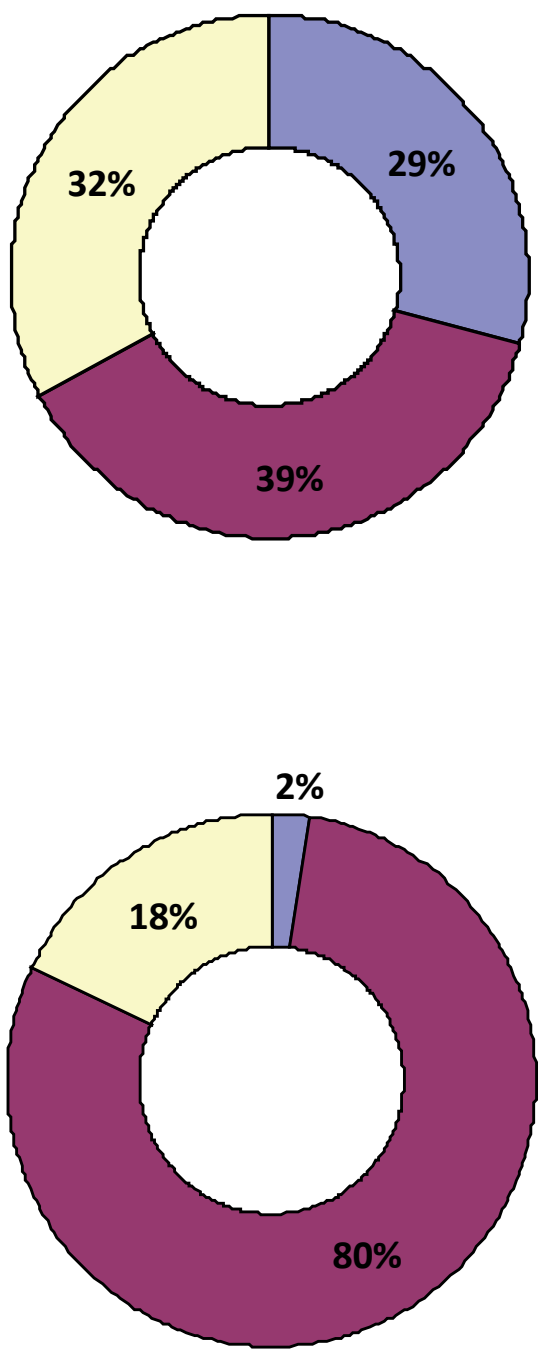

\begin{tabular}{|l|}
\hline$\square S I$ \\
$\square$ NO \\
$\square$ A VECES
\end{tabular}

Gráfico 19: ¿Les das algún tipo de donativo a los músicos por su interpretación?

Muchos son los factores que afectan al donativo percibido por el músico en sus actuaciones. El 10\% de los encuestados afirma que nunca da donativos a los músicos, ante un $10 \%$ que sí lo hace. El $79,58 \%$ a veces compensa a los músicos según el valor y el agrado que genere su actuación al espectador.

Gráfico 20: Ese donativo, ¿̇crees que es molesto que los músicos lo pidan activamente?

La cuestión de tocar en las terrazas sigue siendo un punto de conflicto, la "pida activa" puede resultar desagradable al público ya invade un momento de sociabilización o descanso. Las estrategias del músico son muy variadas y no todos son respetuosos con las distancias al público. El 29\% de los encuestados considera molesto que pidan dinero cuando están parados en las terrazas, especialmente si el músico es muy insistente a la hora de recoger el donativo. El 32\% de los encuestados la considera, solo en ocasiones, molesta dependiendo del comportamiento del músico. El 39\% no le resulta molesto.

Gráfico 21: ¿Crees qué los músicos abusan de la solidaridad de la gente?

El creciente marco legal y el control estricto de las administraciones públicas han involucrado a los músicos en diversos conflictos, ya no solo de convivencia vecinal, sino con los servicios ciudadanos del entramado urbano y su adecuación (Picún, 2013). Pero, en comparación con los últimos veinte años, los músicos han ganado aprecio entre el público que busca alejarse de la frialdad y la monotonía de la música comercial (Macchiarella, 2015). El 2\% de los encuestados asegura sentir ese abuso por parte de los músicos, frente al $18 \%$ de encuestados que lo han experimentado en algún momento, y el $80 \%$ que no. 


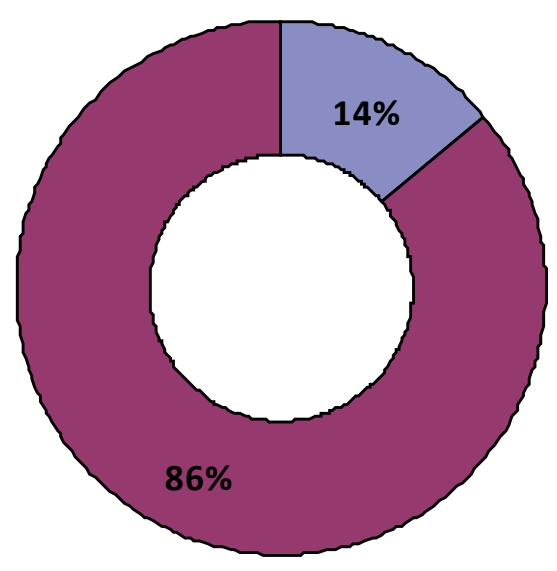

Gráfico 22: ¿Deberían ser músicos profesionales los que interpretan en la calle?

Según Jaques Berne en la introducción de El hombre de la calle ante la obra de arte (Dubuffet, 1973), el artista asume unos esfuerzos a veces desagradecidos ante el resto de profesiones. El tiempo, las preocupaciones, el dinero, el afecto a su medio de expresión... La "rebeldía" a los canales habituales de la música han provocado nuevas formas de expresión que, finalmente, sino profesionalizan la actividad, la encaminará a una mejora en su concepción entre la ciudadanía.

En la calle convergen multitud de actores que usan la calle como medio económico de trabajo: lava coches, vendedores ambulantes... pero el músico u otros artistas de calle interaccionan con la sociedad al ofrecer un espectáculo (Picún, 2013).

Además, lacalleofreceunespaciodeexperimentación diferente, de ensayo y formaciones musicales futuras que encuentran un contacto directo con el público en un espacio libre. Muchos artistas comienzan en la calle, aunque, en su mayoría, el destino sea desatender este espacio en busca de unos nuevos objetivos profesionales. El 86\% piensa que los músicos de calle no deben verse como profesionales, no porque no los consideren dignos de ello sino por la regularización más institucionalizada que implicaría. Pero, en cambio, el $14 \%$ si apoya la profesionalización puesto que sacaría al colectivo de la falta de legitimidad permanentemente en la que se halla.

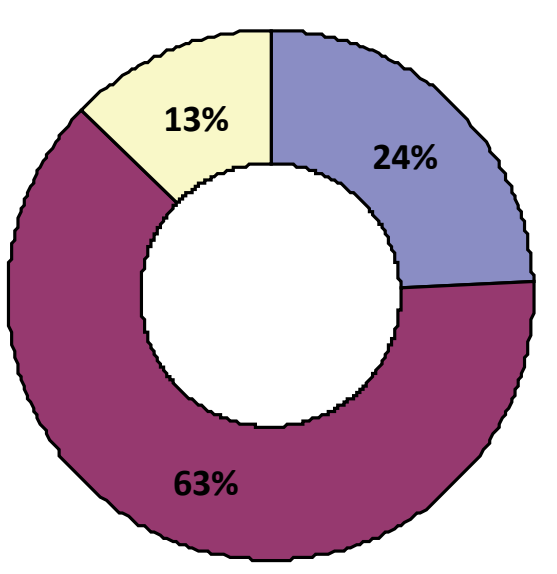

Gráfico 23: ¿Crees que para obtener un permiso deberían pasar un control de calidad?

No podemos evitar extrapolar esta cuestión al caso madrileño que, además de popularizar la música en la calle por los medios de comunicación, desencadenó una cuestión transcendental, la profesionalidad del músico.

El $63 \%$ de los encuestados piensa que la música en la calle no debería someterse a ningún control de la calidad, se sobrentiende que el músico toca por necesidad y es el propio público el que juzgará la actuación.

En cambio, el $24 \%$ considera necesario ese control de calidad, un filtro que regularice la concesión del permiso a los músicos. El 13\% solo en ocasiones, ya que la formación y géneros interpretados de cada músico son variados. 

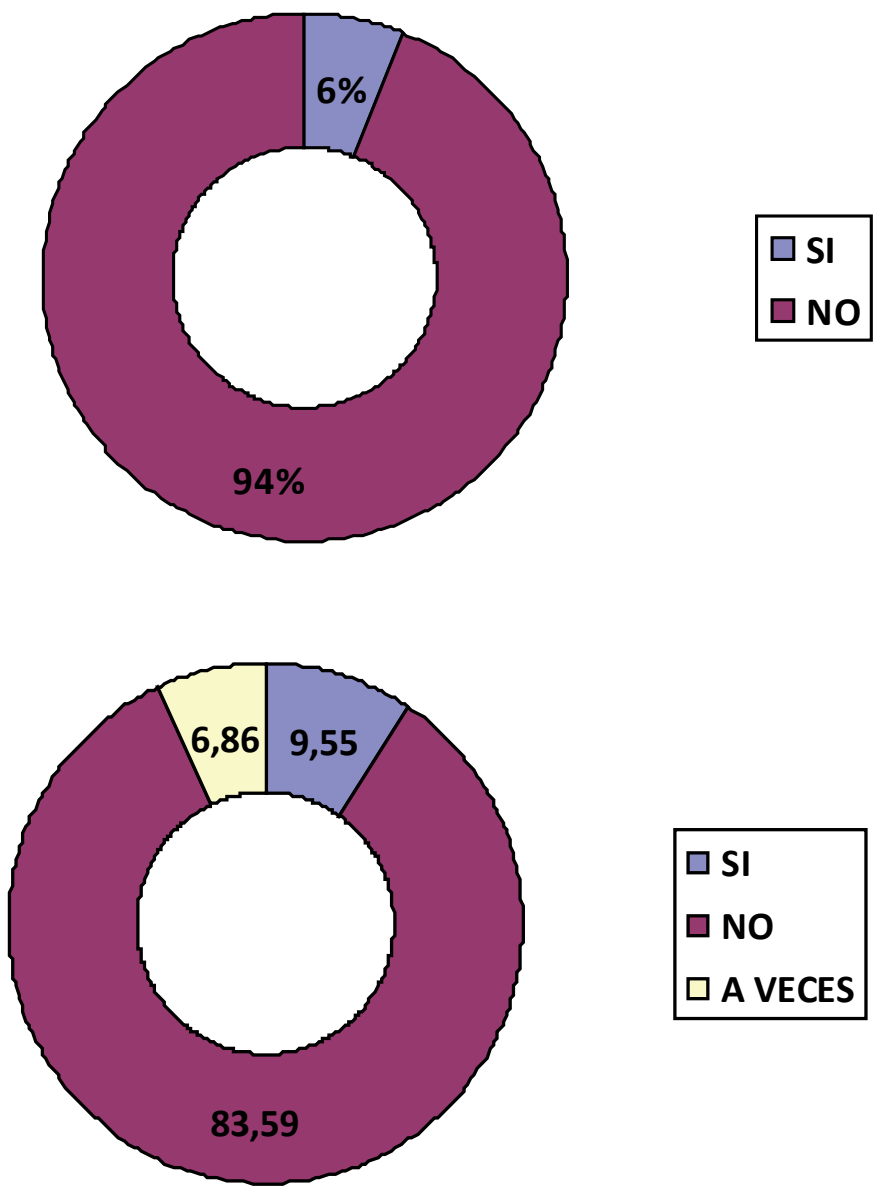

Gráfico 24: ¿Crees que existe un exceso de músicos tocando en las calles?

El $94 \%$ de los encuestados piensa que no existe un exceso de músicos en las calles, frente al 6\% que considera su creciente presencia en los últimos años, en especial con la aparición de colectivos musicales callejeros y el movimiento turístico estival.
Gráfico 25: ¿Deberían los músicos ser multados por ejercer la profesión en la calle?

Existen dos actitudes por parte del ciudadano de calle: que el ciudadano sepa discernir la música callejera de la contaminación acústica, y que el ciudadano tenga una conducta ignorante o ética. El $83 \%$ de encuestados consideran excesivo multar al músico si no dispone de permiso, en cambio el $10 \%$ argumentan, con una justificación de peso, que al margen de la sanción al músico la ley está para cumplirse y nadie está exento de su cumplimiento. En un punto de vista intermedio hallamos al 7\% que argumenta la necesidad de multar o no al músico según las condiciones del hecho y el tipo de negligencia cometida.

Tras analizar los resultados de la encuesta, hemos detectado diversas cuestiones que genera la actividad musical en la calle:

- En primer lugar, la música en directo motiva a las personas a la práctica grupal. El ser humano está acostumbrado a pensar en una respuesta individual y solemos olvidar que, a lo largo de la historia, la música ha sido una actividad grupal (Storr, 2007). El término "acustemología" (o epistemología acústica) es un enfoque teórico y metodológico creado por el profesor estadounidense Steven Feld (2010), para defender el hecho de que escuchar un sonido en una posición espacial inspira una conexión de sentidos y experiencias. Esto instiga la necesidad de reescribe las relaciones entre individuos en base a un conocimiento compartido. El estudio de este fenómeno sonoro relaciona la espacialidad de la música callejera con su público, que no busca otra cosa que la conectividad efímera con otro individuo desmarcando la rutina del día a día. Un elemento que se encuentran en un lugar en común y del cual no hay que hacer colas, pagar una entrada o estar en silencio para disfrutarla con otros (Neve, 2008). En resumen, la música en el entorno urbano tiene un potencial más transformativo que la música escuchada por reproductores móviles. Vivimos en la era del individualismo, donde los espacios no presenciales marcan las nuevas formas 
de relacionarse, por tanto, un nuevo espacio de interacción de dialogo entre el público y los músicos puede ser valorado como recurso cultural (Simpson, 2011).

- En segundo lugar, la música callejera es un producto de consumo indirecto ya que se ha convertido en parte del ocio público. Antiguamente, nuestra organización social usaba lugares muy específicos para la música, que ofrecían una experiencia compartida muy exclusiva. Poco a poco la cultura fue moviéndose a través de círculos más amplios al alcance de todos, gracias a las grandes teorías del pensamiento racional de la esfera pública (Habermas, 1981). Es el caso de la opera que, ahora debido a su larga tradición elitista, ofrece un producto de consumo difícil de difundir. Los públicos no siempre se sienten identificados con la experiencia que se les ofrece. Durante mucho tiempo, algunas personas se encontraban privadas de este consumo y la escucha en lugares públicos libres del mercado del arte han puesto al alcance de todos dicho lujo, sea a través de la música callejera o con iniciativas más ambiciosas como las actuales proyecciones de opera en directo en las plazas de las grandes ciudades europeas (Ruiz, 2015). A través de teorías antropológicas como la de Roberts (2014), vemos que la música juega un papel importante del patrimonio de la ciudad y como ésta es aprovechada como simbolismo cívico de regeneración urbana. La cultura, al fin y al cabo, gira en esa necesidad de distracción que todos tenemos y que es cubierta por las tendencias de mercado.

- En tercer lugar, el arte callejero continúa siendo una profesión cuestionada. Según algunos de los encuestados, si la música callejera no es considerada profesional no es tanto por el acto en sí de pedir dinero, sino porque los músicos profesionales ya disponen de lugares pensados para su oficio. En defensa de la calle observamos la ocupación de un espacio experimental y de primer contacto con el público. Todos los artistas fueron amateurs en sus comienzos y necesitan romper barreras con el público a través de una actividad más bien coyuntural que puede convertirse en el eje principal de su trabajo. Por ejemplo, a partir de los años 80, con los movimientos artísticos urbanos, la reconversión del Street art en un producto comercializado dio lugar a nuevos espacios de intercambio social (García, 2015). También se debe tener en cuenta que cuando el arte informal pasa a una sala expositiva o una sala de conciertos, pierde ese encanto que lo caracteriza al ser mediatizado y politizado (Aricó y Stanchieri, 2014). El arte urbano se considera precisamente arte por crear una tendencia libre de academicismos y con un proceso creativo producto de la liberación del ser con un enriquecimiento más amplio debido a la carga moral y política que conlleva. Igualmente, no descartamos los filtros necesarios para evitar fraudes, gente que no tiene conocimientos musicales y que accede a la calle encubierto de una música que resulta ser mendicidad. Un ejemplo de filtro efectivo lo hallamos en México, donde se tuvo que realizar el empadronamiento de 1500 músicos para poder controlar los numerosos artistas que actuaban en la ciudad (Santana, 2009). Un músico callejero concienciado siempre evitará exhibirse sin unos criterios que sean del agrado del público. 
- En cuarto lugar, la música en la calle está condicionada por el entorno urbano. El ritmo de vida actual es más ruidoso de lo que era hace unos años y la música tiene que competir contra el resto de sonidos de la ciudad. Se han originado auténticas polémicas de gestión ambiental en las grandes ciudades debido a esta "bruma sonora" que anula el silencio con la hegemonía de caracteres sonoros existentes. De ello se reduce, en parte, las condiciones de reflexión que sustentan la comunicación y convivencia urbana entre los ciudadanos (Fortuna, 2009). La música callejera ha tenido que afrontar el estado de distracción que supone esta contaminación mejorando la calidad sonora o la puesta en escena, llegando a ser considerada desorden, polución y agresión ambiental. La música ha pasado a ser un ruido que genera rechazo en quien lo percibe ya que el receptor crea un escudo entorno a una realidad existente pero no analizada por si mismo (Méndez, 2016), es decir, el vecino o el comerciante no tienen en cuenta el resto de sonidos generados por el paisaje urbano que cohabitan con el músico que ha de hacerse denotar sobretodos ellos. La diferencia que existe entre música y ruido reside en que la música cuenta con el ruido como un elemento activo y creativo (Attali, 1977). La atención del público, en el caso de los músicos, solo puede obtenerse a través de un reclamo sonoro o escénico, por tanto, la música en la calle requiere un trabajo de campo donde su evaluación no este sentenciada a la contaminación acústica de la ciudad.

- En quinto lugar, la gestión actual que regula la calle no siempre es equitativa a las necesidades de los artistas. En algunas ocasiones, la música callejera ha sido víctima de episodios desagradables debido a la intervención policial, normalmente bajo denuncia vecinal. No podemos extendernos en que función cumple cada agente implicado y las responsabilidades de cada uno en este tipo de situaciones, pero para comprender mejor la implicación ciudadana disponemos de un ejemplo. El 3 de septiembre de 2013 Jonathan, músico colombiano, fue abordado por la policía y presionado a dar su instrumento debido a la denuncia de un vecino de la zona del Mercado Central de València. La intervención de la gente que pasaba por allí o comía en las terrazas evitó su detención (Atlas, 2013). Otro ejemplo, donde la implicación ciudadana es menos directa pero ha traído consecuencias similares a los artistas y que consideramos digna mencionar, es el caso de las conocidas "estatuas vivientes" de las Ramblas de Barcelona que, tras años de ser un símbolo de encuentro entre turistas, fueron replegados al final del paseo. La lucha con el gobierno local, que instauró dicha medida, llevó a cabo este traslado para facilitar la circulación de los transeúntes que se detenían a contemplar las actuaciones, dificultando el paso de la zona y poniendo en peligro la seguridad (López, 2012). Estos ejemplos muestra un diseño de normativas muy restrictivas y de gestión rápida, condicionadas al no tener referentes, y de las cuales parte de la población no comparte.

- En sexto lugar, el intercambio entre artista y público no es únicamente económico. Normalmente cuando se habla de donativos la gorra es el hilo de comunicación entre el artista y el público. La decisión del artista que toca en la calle cuenta con diversas 
intenciones que, como bien menciona Silva E Sousa (2017) en su estudio de los músicos de calle de Madrid, pasa por la realización de una serie de intercambios materiales y simbólicos. Pasando por las teorías de Jeannot (2008) y Klatzmann (1985), observamos la importancia del trabajo informal como sistema económico escogido por una cuestión más amplia que el de la economía formal, es decir, la precariedad laboral y las adaptaciones a la sociedad actual han llevado a los músicos a un nuevo concepto económico donde no solo se busca dinero sino identidad y reconocimiento (Picún, 2014). Muchos músicos no se limitan a pedir, muestran un producto efímero y sin un valor inicial. Sea con la promoción y venta de discos o de una nueva experiencia que genere un recuerdo, el trabajo del músico va más allá del interés económico, buscan un motivo ideológico fuera de los canales convencionales. Flavio explica como el músico busca esta fluctuación en su trabajo, como busca mimetizarse con el entorno para no ser olvidado por el público como si de una performance se tratase.

\section{CONCLUSIONES.}

Tras nuestro estudio, hemos observado que cada pregunta ha originado una serie de opiniones muy variadas. En general, la gran mayoría de encuestados considera a los músicos de forma positiva y opinan que sus condiciones deberían ser mejoradas con alternativas más detalladas y estudiadas.

Muchos son conscientes de que queda por delante un proceso largo de reconocimiento y valoración profesional en este gremio. Continúa habiendo un debate sobre el "servicio" que ofrece la música en la calle, que cada vez resulta más accesible y participativo con las iniciativas de asociacionismo entre músicos de calle.

La música callejera forma parte de una ecuación en la que, a más conocimientos del tema, mayor es la apropiación del sentido de comunidad con el espacio donde se desarrolla. En muchos casos, el oyente no es consciente de las novedades del entorno ambiental hasta que su actividad se ve alterada, positiva o negativamente, por dicho cambio. Es en este pensamiento donde el músico callejero debe tener mucho cuidado en proporcionar calidad a su actuación y respetar unos mínimos criterios de convivencia, porque un uso inadecuado del espacio puede traer un espacio marginal e inseguro por el cual será rechazado.

Para muchos resulta evidente se trata de un trabajo, una actividad que genera ocio y, por tanto, ingresos. Pero, la música en la calle está siendo considerada como un arte independiente de todo organismo; gratificante, emotiva y viva...una expresión artística cuya existencia es ineludible y que, cada vez más, está encontrando su lugar en la calle, su paisaje experimental por excelencia. Por tanto, la música callejera ha pasado a ser una intervención de poderosas características sociales y culturales, y como tal, tiene todas las papeletas para, poco a poco, ser puesta en valor dentro de los nuevos procesos creativos urbanos de la ciudadanía. 


\section{REFERENCIAS BIBLIOGRÁFICAS.}

ABASCAL, Elena, GRANDE, Ildefonso. (2005). Análisis de encuestas. Madrid: ESIC Editoriales. ISBN: 9788473564205.

ALBÁN, Adolfo. (2008). Arte y espacio público: ¿̇un encuentro posible?. Calle14: revista de investigación en el campo del arte [en línea], 2, 2, 104-111. Disponible en: http://www.redalyc.org/pdf/2790/279021515011.pdf

ALONSO, Luis, ALVIRA, Francisco, GARCÍA, Manuel; MODESTO, Rafael. (2016). El análisis de la realidad social. Métodos y técnicas de investigación. Madrid: Alianza. ISBN: 978-84-9104-111-5.

ARICÓ, Giuseppe, STANCHIERI, Marco Luca. (2014). El discreto encanto del "espacio público". Diagonal [en línea], 38. Disponible en: http://www.revistadiagonal.com/articles/analisi-critica/el-discreto-encanto-del-espacio-publico/

ATLAS. (4 de septiembre de 2013). Doce policías reducen a un músico callejero por exceso de ruido en Valencia. El Mundo [en línea]. Disponible en: http://www.elmundo.es/elmundo/2013/09/04/valencia/1378316780.html

ATTALI, Jacques. (1977). Ruidos: ensayo sobre la economía política de la música. Madrid: Siglo XXI editores. ISBN 96823-1970-6.

BENNETT, Elizabeth, MCKAY, George. (2019). From Brass Bands to Buskers: Street Music in the UK. Norwich: Arts and Humanities Research Council/ University of East Anglia [en línea], pp.4. Disponible en: https://ueaeprints.uea.ac.uk/ id/eprint/70955/1/Bennett_McKay_Street_Music_report_interactive.pdf

BENNETT, Andy, ROGERS, Ian. (2014). Street Music, Tehcnology and Urban Soundscapes. Journal of Media \& Cultural Studies: Continuum [en línea], 28, 456-464. Disponible en: https://www.tandfonline.com/doi/abs/10.1080/1030431 2.2014.893991

BLACKING, John. (2006). ¿Hay música en el hombre?. Madrid: Alianza. ISBN: 978-84-206-8781-0.

BOURDIEU, Pierre. (2010). El sentido social del gusto. Buenos Aires: editores siglo veintiuno. ISBN: 978-987-629123-1.

BOURRIAUD, Nicolas. (2009). Radicante. Buenos Aires: Adriana Hidalgo Editora. ISBN: 978-987-1556-12-0.

BRAYSHAY, Mark. (2005). Waits, musicians, bearwards and players: the inter-urban road travel and performances of itinerant entertainers in sixteenth and seventeenth century England. Journal of Historical Geography [en línea], 31 (3), 430-458. Disponible en: https://www.sciencedirect.com/science/article/abs/pii/S030574880500006X?via\%3Dihub

CLUA, Alvaro, LLORCA-BOFÍ, Josep, PSARRA, Sophia. (2020). Urban opportunities and conflicts around street musicians: the relationship between the configuration of public space and outdoor acoustics in Ciutat Vella, Barcelona. Journal of Urban Design [en línea], February. Disponible en: https://www.tandfonline.com/doi/full/10.1080/13574809.2019. 1699398

COHEN, Sara; LASHUA, Brett, SCHOFIELD, John. (2010). Popular music, mapping, and the characterization of Liverpool. Popular Music History [en línea], 65-83. Disponible en: https://urbanheritages.files.wordpress.com/2011/11/pmh_ article-lashua-cohen-schofield-1.pdf

CONNELL, John, GIBSON, Chris. (2005). Music and tourism: on the road again. UK: Channel View Publications. ISBN: 1-873150-93-8.

DUBUFFET, Jean. (1973). El hombre de la calle ante la obra de arte. Madrid: Debate. ISBN: 9788474446197.

ESPAÑA. (2017). Real Decreto 1039/2017, de 15 de diciembre, por el que se declaran oficiales las cifras de población resultantes de la revisión del Padrón municipal referidas al 1 de enero de 2017. BOE [en línea], 316, $130530-130535$. Disponible en: $h$ ttps://www.boe.es/boe/dias/2017/12/29/pdfs/BOE-A-2017-15820.pdf

ESPAÑA. (2003). Ley 58/2003, de 17 de diciembre, General Tributaria. BOE [en línea] 302, de 18 de diciembre de 2003. Disponible en: https://boe.es/buscar/act.php?id=BOE-A-2003-23186

FELD, Steven. (2010). Acustemology. L'epos: Spazi sonori della música [en línea]. Palermo: L’EPos. Disponible en: https://static1.squarespace.com/static/545aad98e4b0f1f9150ad5c3/t/55bb04b4e4b0acc417643251/43831979693 7/2010+Acustemologia.pdf

FERRO, Germán. (2009). Guías de observación y valoración cultural. Revista Apuntes [en línea], 22, 1, 34-53. Disponible en: http://www.scielo.org.co/pdf/apun/v23n2/v23n2a07.pdf

FORTUNA, Carlos. (2009). La ciudad de los sonidos. Una heurística de la sensibilidad en los paisajes urbanos contemporáneos. Cuadernos de Antropología Social [en línea], 30, 39-58. Disponible en: http://www.scielo.org.ar/ scielo.php?script=sci_arttext\&pid=S1850-275X2009000200003 
GARCÍA, Belén (2015). Grafiti y postgrafiti en la ciudad de Valencia: una perspectiva crítica. C. Senabre Llabata. Tesis doctoral, Universidad de Valencia [en línea]. Disponible en: http://roderic.uv.es/bitstream/handle/10550/45854/ Tesisdigitalcompleta\%20Belén\%20Garc\%C3\%ADa\%20Pardo3.pdf?sequence=2\&isAllowed=y

GARSÁN, Carlos. (30 de mayo de 2019). Los músicos callejeros de València quieren soluciones (y no multas). CulturPlaza: ValenciaPlaza [en línea]. Disponible en: https://valenciaplaza.com/los-musicos-callejeros-de-valenciaquieren-soluciones-y-no-multas

HABERMAS, Jürgen. (1981). Historia y crítica de la opinión pública: transformación estructural de la vida pública. Barcelona: Gustavo Gili. ISBN: 9788425227080.

JEANNOT ROSSI, Fernando. (2008). "Desarrollo de la economía informal”, Análisis Económico [en línea], 52, Universidad Autónoma Metropolitana Unidad Azcapotzalco, 133-158. Disponible en: http://www.redalyc.org/ pdf/413/41311484009.pdf

KLATZMANN, Rosine. (1985). El trabajo negro y la economía del mañana. Barcelona: Planeta ISBN: 84-320-7871-9.

LÓPEZ, Helena. (18 de febrero de 2012). Las estatuas de la Rambla se organizan contra el traslado. El Periódico [en línea]. Disponible en: http://www.elperiodico.com/es/barcelona/20120218/las-estatuas-de-la-rambla-se-organizancontra-el-traslado-1425893

MACCHIARELLA, Ignazio. (2015). Suoni osteggiati note sulla busking music. Medea: rivista internazionale di studi interculturali [en línea], 1, 1. Disponible en: http://dx.doi.org/10.13125/medea-1852

MARCOS CASQUERO, Manuel Antonio. (1997). El mundo de los Goliardos y clérigos vagabundos. Estudios Humanísticos y filología [en línea], 19. Universidad de León. Disponible en: https://dialnet.unirioja.es/descarga/articulo/104880. $p d f$

MÁRQUEZ, Israel V. (2011). Música y experiencia: de las sociedades primitivas a las redes sociales. AlBR: revista de antropología iberoamericana [en línea], 6, 2, 193-214. Disponible en: http://www.redalyc.org/pdf/623/62322211004. pdf

MARTínEZ GIL, Alicia. (2014). Análisis de gestión de los músicos callejeros . (directores). Trabajo fin de Master, Universidad Politécnica de València. Disponible en: https://riunet.upv.es/handle/10251/117605

MARTÍNEZ, Berriel. (2011). El género de la música en la cultura global. TRANS: Revista Transcultural de Música [en línea], 15, 2-17. Disponible en: http://www.redalyc.org/articulo.oa?id=82222646024

MARTÍNEZ, Pascual. (1996). Los goliardos desaparecieron hace siete siglos. Aldaba: revista del Centro Asociado a la UNED de Melilla [en línea], 28, 459- 474. ISSN: 0213-7925. Disponible en: https://dialnet.unirioja.es/descarga/ articulo/1300917.pdf

MÉNDEZ, Antonio. (2016). Política del ruido. En los límites de la comunicación musical. Methaodos revista de ciencias sociales [en línea], 4, 1, 21-35. Disponible en: http://dx.doi.org/10.17502/m.rcs.v4i1.101

MESA EDITORIAL MERCA2.0. (2015). ¿Cuál es la edad que predomina en las principales redes sociales?. Merca 2.0 [en línea]. Disponible en: https://www.merca20.com/cual-es-la-edad-que-predomina-en-las-principales-redes-sociales/

MOS, Lucía. (30 de enero de 2020). Madrid recorta las autorizaciones a los músicos callejeros del centro. Madrid Secreto [en línea]. Disponible en: https://madridsecreto.co/madrid-recortara-las-autorizaciones-a-los-musicoscallejeros-del-centro/

NEVE, Eduardo. (2008). Geografía experiencial a la escucha. Tesis doctoral [en línea]. Universidad Autónoma Metropolitana- Iztapalata México. Disponible en: http://dcsh.izt.uam.mx/licenciaturas/geografia_humana/wpcontent/uploads/2014/11/Tesina-Eduardo-Neve-2008.pdf

NÚÑEZ-VARELA Y LENDOIRO, José Raimundo. (1946). La ocupación de Betanzos y su tierra por los franceses en 1809: 163 días de suplicio en La Voz del Pueblo. A Coruña: Ayuntamiento de Betanzos.

PICÚN, Olga. (2013). ¿Mendigo, vendedor ambulante, delincuente, o...músico?. Quaderns-e de l'ICA [en línea], 18, 2, 81-95. Disponible en: https://www.raco.cat/index.php/QuadernselCA/article/view/274291

PICÚN, Olga. (2014). Legitimación social de las prácticas de músicos callejeros: una mirada a la construcción de vínculos de reciprocidad, en Memoria de las Jornadas de Extensión 2013: Musicología en el Uruguay: Aportes a la construcción de su campo de estudio. Montevideo. 
POL, Enric, VALERA, Sergi. (1994). El concepto de identidad social urbana: una aproximación entre la Psicologia Social y la Psicologia Ambiental. Universitat de Barcelona: Anuario de Psicologia [en linea], 62, 5-24. Disponible en: https:// www.raco.cat/index.php/anuariopsicologia/article/viewFile/61126/88865

REMESAR, Antoni, RABA, Adolf, , RICART, Núria, VIDAL, Tomeu. (2006). Sis aspectes de la participació en processos de transformació urbana. Quaderns d'Educació Social [en línea], 8, 63-72. Disponible en: https://www.raco.cat/index. php/QuadernsEducacioSocial/article/view/347933/439120

ROBERTS, Les. (2014). Marketing musicscapes, or, the political economy of contagious magic. Tourist Studies [en línea], 14, 1. Disponible en: https://www.researchgate.net/profile/Les_Roberts/publication/270721238_Marketing_ musicscapes_or_the_political_economy_of_contagious_magic/links/58de53c0458515add90667de/Marketingmusicscapes-or-the-political-economy-of-contagious-magic.pdf

RUIZ MANTILLA, Jésus. (9 de mayo de 2015). La ópera sale a la calle y entra en casa. El País [en línea]. Disponible en: https://elpais.com/cultura/2015/05/08/actualidad/1431107858_704561.html

SANTANA, Luis. (2009). Tradición musical en Zacatecas (1850-1930): una historia sociocultural. Zacatecas: Instituto Zacatecano de Cultura "Ramón López Velarde". ISBN: 978-968-5789-52-3.

SENNETT, Richard. (2001). En el limite: la vida en el capitalismo global: la calle y la oficina: dos fuentes de identidad. A. Giddens y W. Hutton. Barcelona: Tusquets. ISBN: 84-8310-737-6.

SILVA E. SOUSA, Flavio Henrique. (2017). Música callejera en Madrid: entre el arte y el ruido. Tesis Doctoral. Dirigida por Paloma Gómez Crespo [en línea]. Universidad Autónoma de Madrid.

SIMPSON, Paul. (2011). Street performance and the city: public space, sociality, and intervenning in the everyday. Space and Culture [en línea], 14, 4, 415-430. Disponible en: http://citeseerx.ist.psu.edu/viewdoc/download?doi=10.1 .1.1034.6042\&rep=rep1\&type $=p d f$

STORR, Anthony. (2007). La música y la mente. El fenómeno auditivo y el porqué de las pasiones. Barcelona: Paidós. ISBN: 978-84-4932119-1.

TORRES, María Alejandra. (11 de febrero de 2011). Los músicos callejeros de Madrid "protestan" tocando. El País [en línea]. Disponible en: http://sociedad.elpais.com/sociedad/2011/02/11/actualidad/1297378811_850215.html 